\title{
آليات تحقيق الانتشار السكاني بالمدن السياحية بالتطبيق على مدينة الغردقة العياحية
}

هبة يسرى محمد سليط

وزارة السياحة
عزت أبو السعود محمد

المعهز العالي اللسياحة والفنادق كينج مريوط

تلتمتع مصر بإمكانات سباحية لا بستهان بها موز عة على ولى كامل أر اضيها من أماكن تاريخية و أثرية

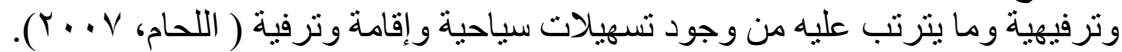

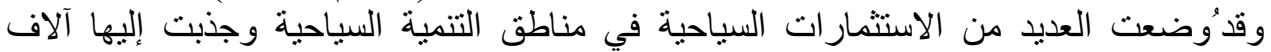

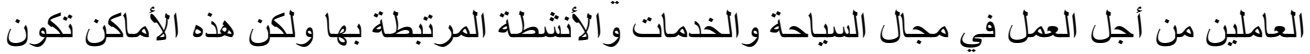

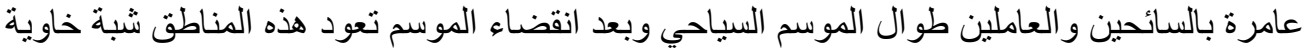

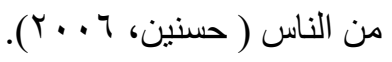

فالنشاط السياحي في العديد من المناطق السياحية يكون منعزل عن المناطق المأهولة بالسكان بحكم

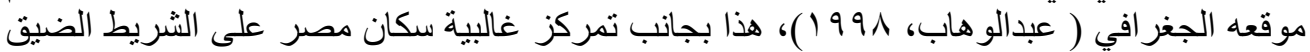

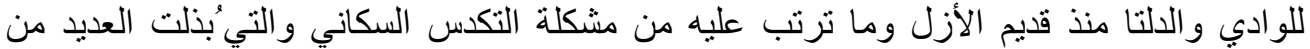

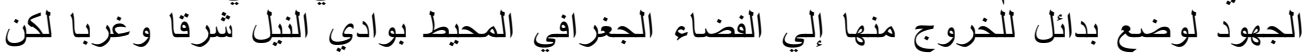

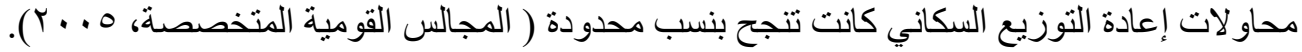

الكلمات الدالة: المشكلة السكانية، التنمية السياحية المتكاملة، التخطيط الإقليمي.

مقدمة: تجمع المصريون القدماء على ضفاف نهر النيل و وعلى أراضي الألتا نتيجة لتوفر المياه

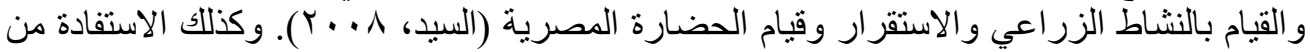

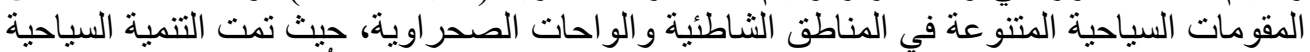

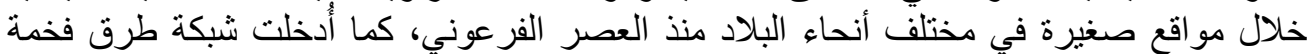

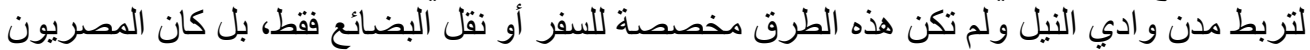

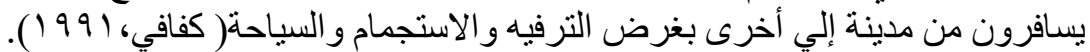

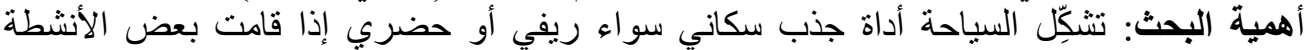

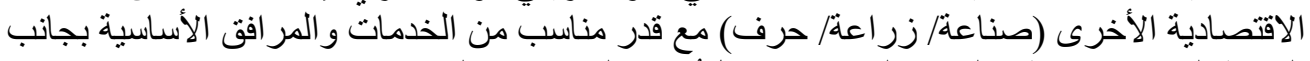
النشاط السياحي بمناطق التنمية السياحية كعاملُ دحفز للاستقر ار الدائم.

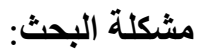

بالر غم من انتشار المناطق و المدن السياحية على كامل أر اضي مصر إلا أن هذه الأمساكن تكون

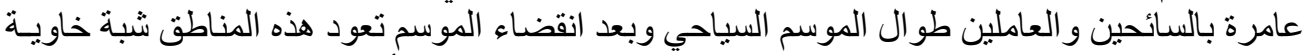

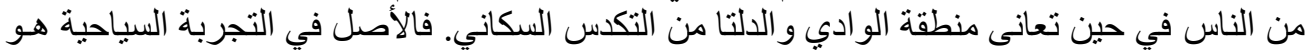

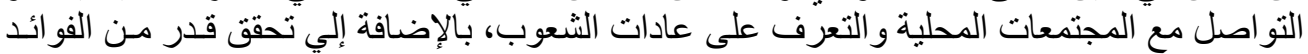
الاقتصادية للنشاط السياحي مع بعض الأنشطة الاقتصادية الأخرى. 
أهداف البحث: تهدف البحث إلي توصيف خريطة السكان في المناطق السياحية واستجابتها لخطط التنمية السياحية كما تهدف إلي: الئي

دراسة التوسع السكاني المرتبط بالتنمية السياحية.

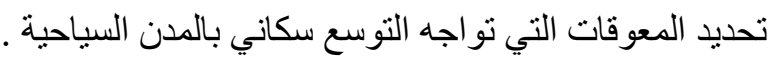
وضع آليات إقامة مجتمعات جديدة بمناطق التنمية السياحية.

فروض البحث: تقوم البحث على اختبار الفروض التالية: الفرض الأول: تتوفر بالمدن السياحية مقومات الاستقر ار الدائم.

الفرض الثاني: توجد بعض العوامل التي تعوق الاستقرار الدائم بالمدن السياحية. • الفرض الثالث: إحداث ظهير تنموي متكامل بالمدن السياحية له أثر ايجابي تحقيق التوازن

أدبيات البحث: تباين إنثاء التجمعات السكانبة علي ضفتي النهر وذللك تأثراً بالعو امل الجوية حيث

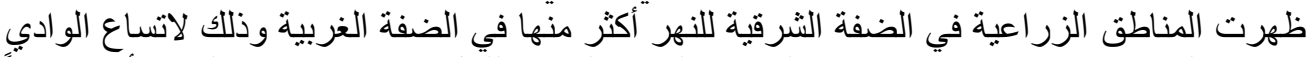

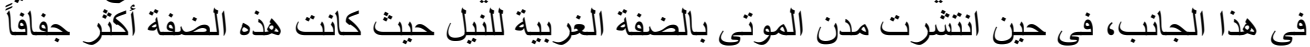

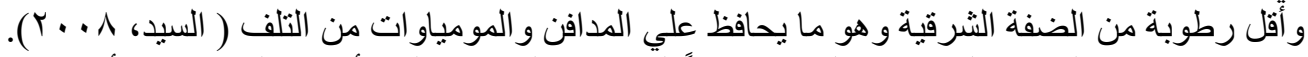

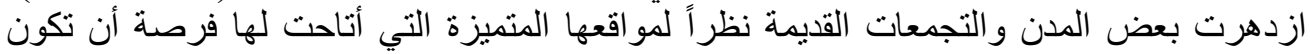

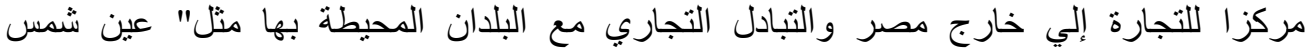

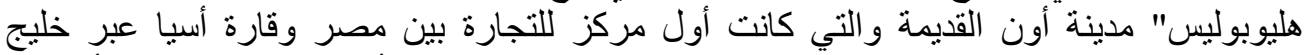

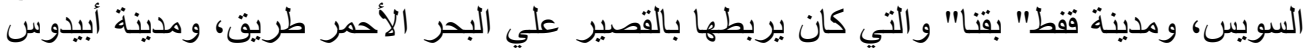
ومدينة الإسكندرية و غير ها من الدن ذات الأهمية التجارية (سلسلة قضايا التنمية، ب . . ب).

الانتثار السكاني بمصر

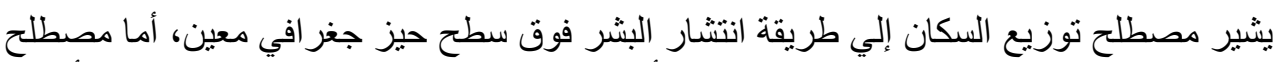

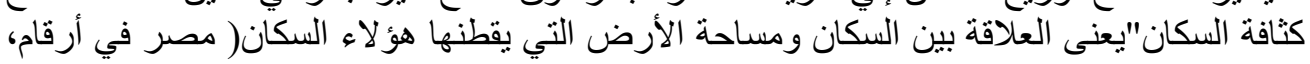
$(Y \cdot) \mathrm{V}$ وتُُعد جمهورية مصر العربية من أعلى الكثافات السكانية في الوطن العربي والعالم (الوهيد،

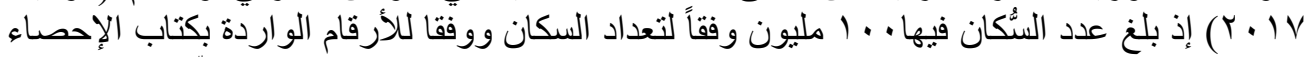

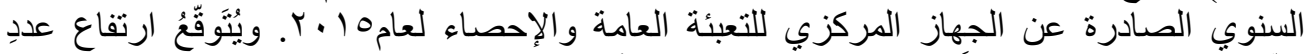

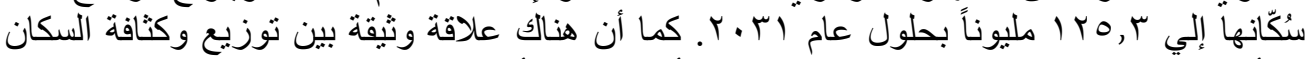

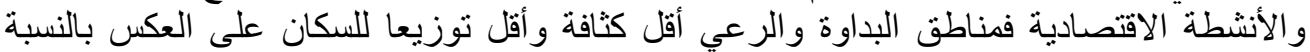

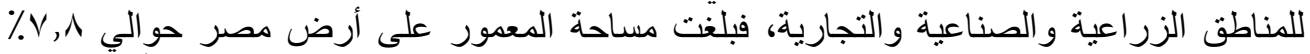

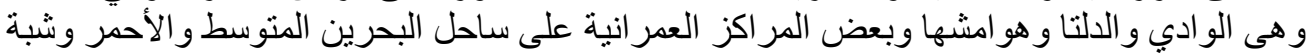

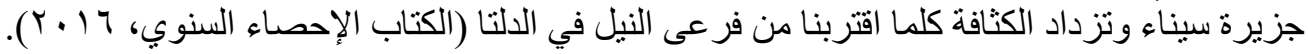


حيث تركزت الاستثمار ات الاقتصادية والخدمية من مصانع وشركات في مناطق محدودة دون التوجه

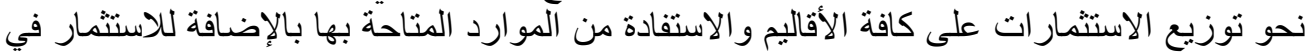

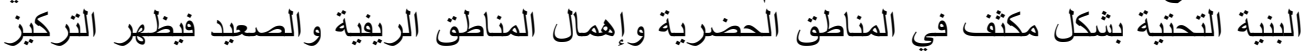

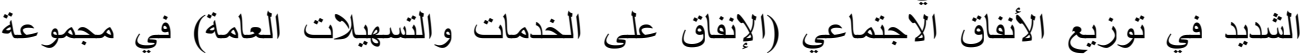

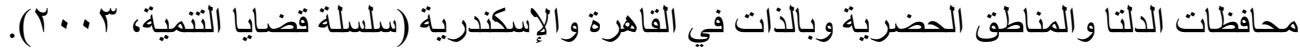

\section{الأثار المترتبة على زيادة الكثافة السكانية \\ أثر زيادة الكثافة السكانية على الأحوال المعيشية زئه}

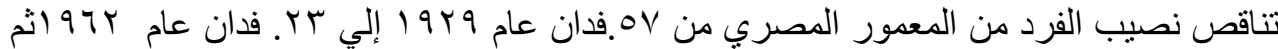

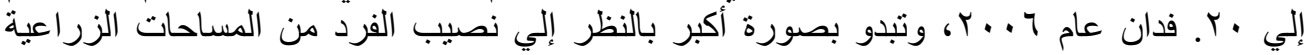

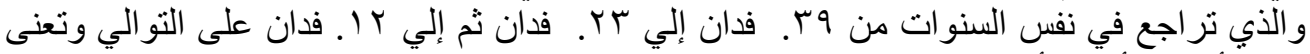

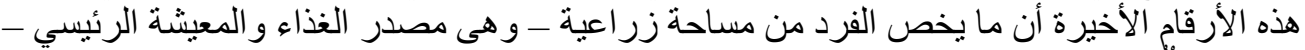

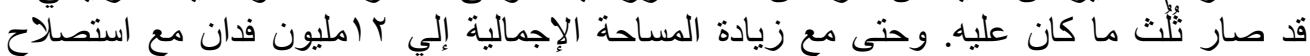

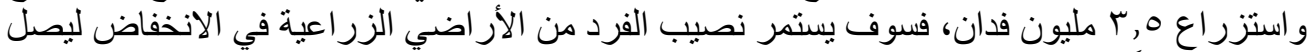

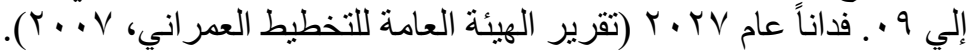

\section{أثر زيادة الكثافة السكانية على الأراضي الزراعية الإنية

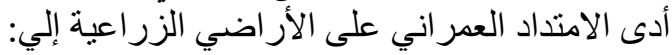

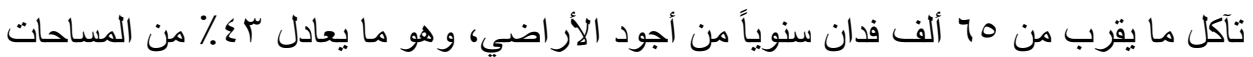

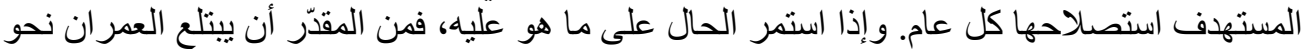

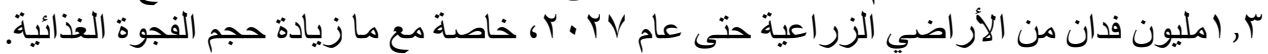

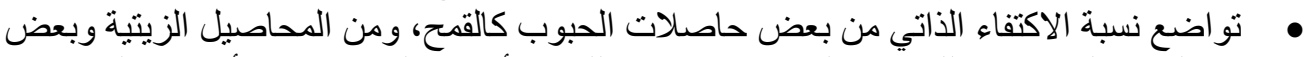

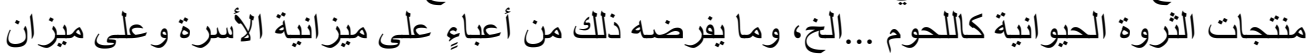
المدفو عات بوجه عام (تقرير المخطط الاستر اتيجي للصحر اء الغربية، 7 ( • ب).

أثر زيادة الكثافة السكانية على المناطق الحضرية

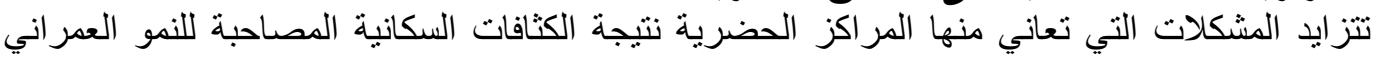

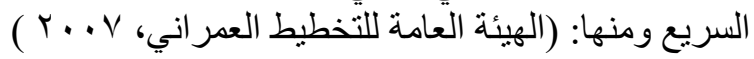

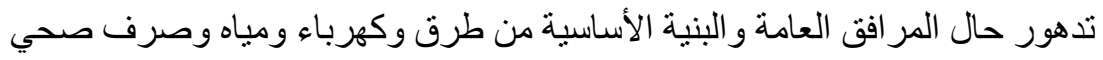

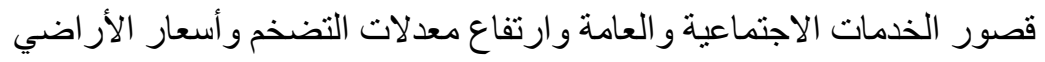

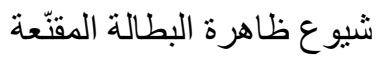
انتثار الازدحام و الضوضاء و التلوث ظهور المناطق الفقيرة حول مداخل المدن و أطر افها، وانتشار العشو ائيات. 
يوجد في مصر بعض أهم المقومات السياحية سواء كانت أثرية وتاريخية أو ترفيهية أو علاجية أو أحداث

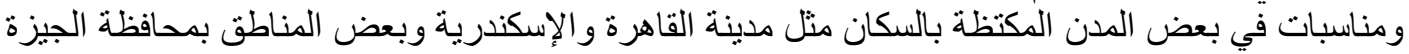
و التي تعاني من التلوث و الضوضاء و والزحام المروري مما يسبب تجنب السائحين لمثل هذه المناطنق السياحية

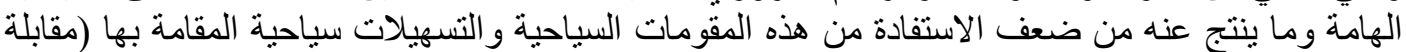

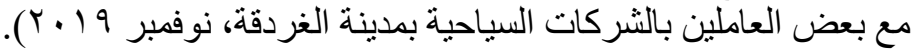

الاتنشار السكاني المرتبط بمشروعات التنمية السياحية

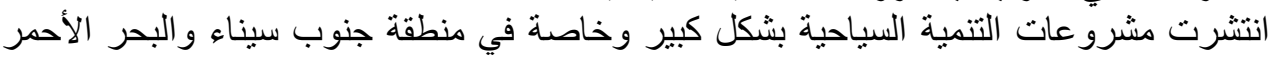

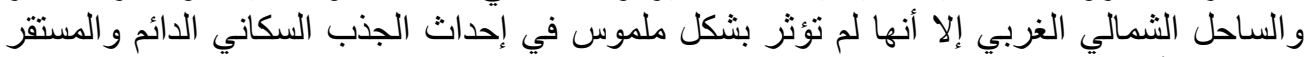

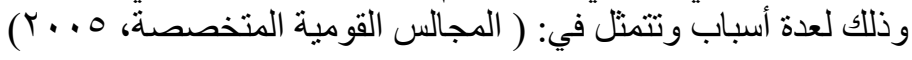
• أن المشرو عات السياحية و الفندقية تكون أكثر ربحية إذا تم تسكين العاملين بها دون أسر هم في

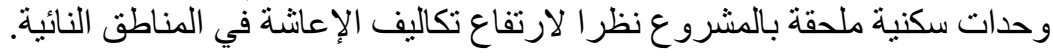
• التذبذب الثديد في حجم النشاط السياحي يجعل الاستقرار والاستدامة للعمال وأسرهم أمرا محفوفا بالمخاطر العالية.

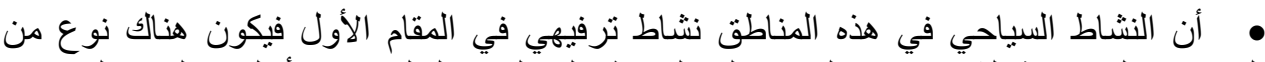

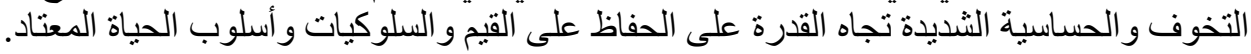
• لم يكن الانتشار السكاني هو الهدف الأساسي في إقامة هذه المشروعات بل كان هدفا ثانانويا خادما للهدف الأول و هو زيادة الإنتاج القطاعي.

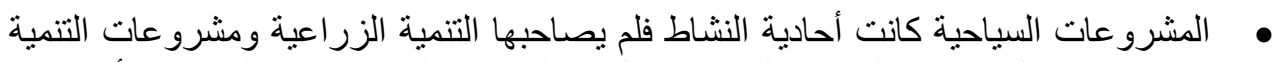
صناعية والإنتاج الحيواني والحرفي التي توفر العون لبعضها البعضة البعض في حالة تباطؤ أو توقف أحدها لسبب أو لآخر.

تعدد الوزارات والهيئات التي تتولى إدارة التنمية بمجالاتها المختلفة دون أن تجمعها

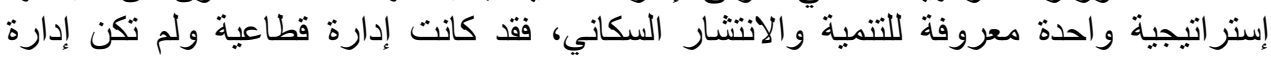

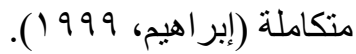

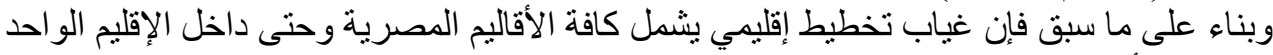

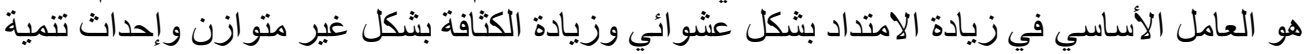

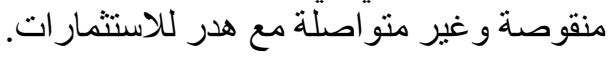

منهجية البحث: طبق البحث على عينة عشوائية من العاملين بالمجال السياحي بمدينة الغردقة بلغ البغ البه

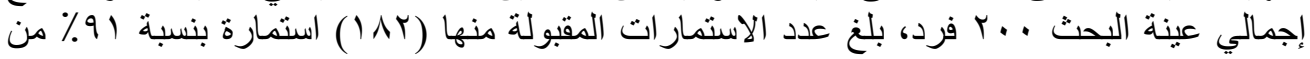

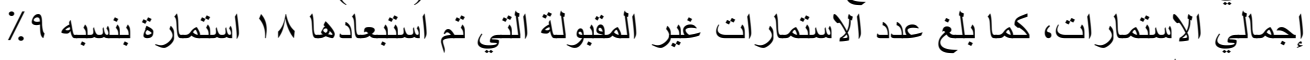
من عينة البحث.

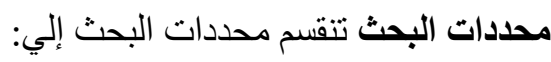
ـ محددات مكانية وتتمثل في مدينة (الغردقة السياحية) بمحافظة البحر الأحمر باعتبار ها أحد المدن

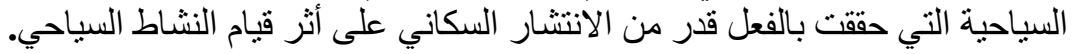

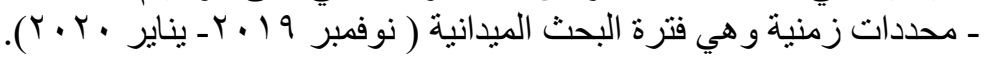


مجتمع وعينة البحث: يتكون مجتمع البحث من العاملين بالمنشآت السياحية الحكومية المنتلة في والمئي

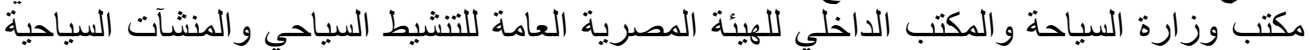

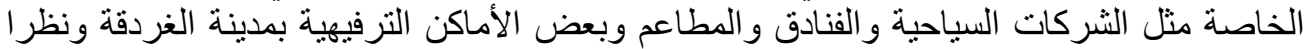

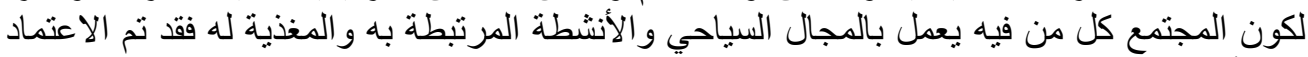
على أسلوب العينة العشو ائية.

تصميم استمارة الاستبيان:ُصمدت استمارة الاستبيان بناءاً على نو عية وكمية البيانات المطلوبة وفقا

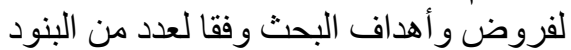
البند الأول: تقييم مستوى الخدمات في المدينة السياحية محل البحثث.

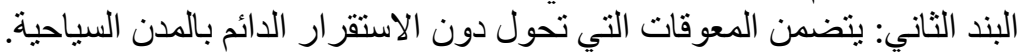

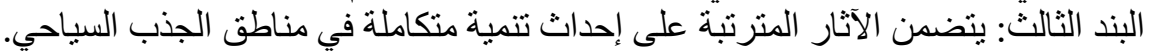
البند الر ابع: الآليات المقترحة لتحقيق التوطين السكاني بالمدن السياحية.

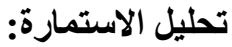

أولا: البيانات الثخصية لأفراد عينة البحث و هم العاملين بالمجال السياحي بهدف تحديد الفئة التي لايها

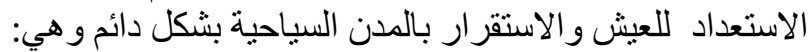

\begin{tabular}{|c|c|c|}
\hline النسبة & العدد & الفئة العمرية \\
\hline$\% 9 r, 0$ & 171 & |Y_O_كنة \\
\hline$\% \vee, 0$ & $1 \varepsilon$ & أكثر من 0؛ سنة \\
\hline
\end{tabular}

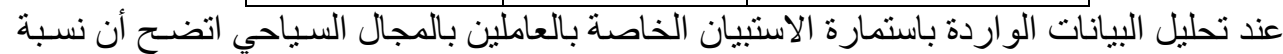

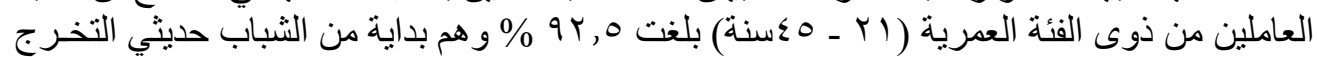

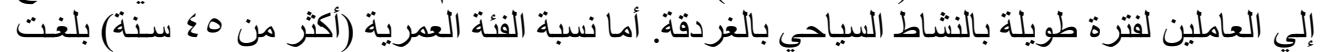

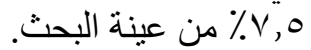

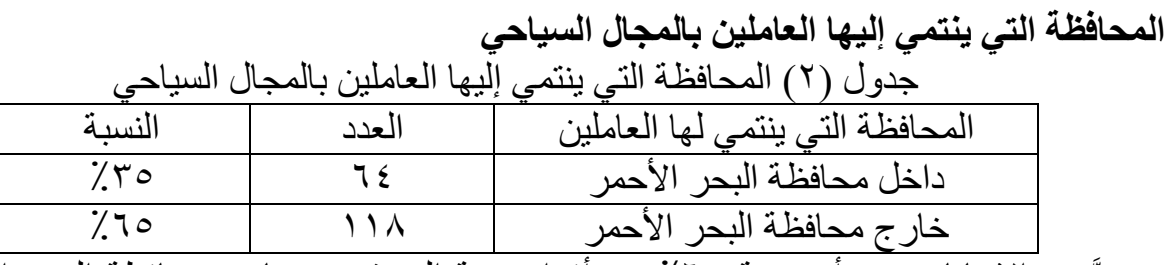

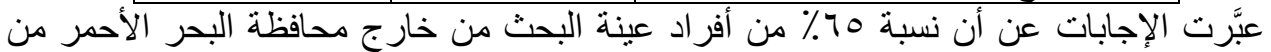

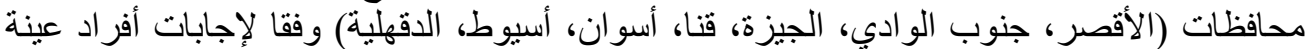

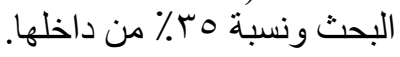




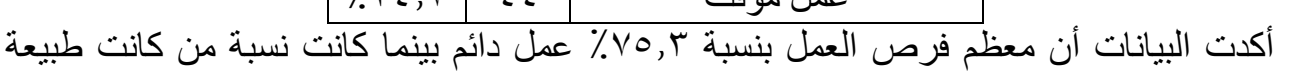

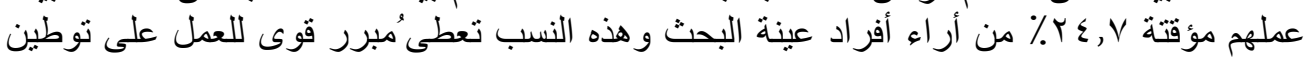

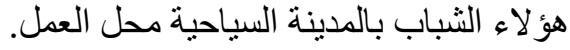

\begin{tabular}{|c|c|c|}
\hline النسبة & العدد & مدة العمل بالمجال السياحي \\
\hline$\%$ \% & $\Delta r, V T$ & اسنة ـ هسنوات \\
\hline$\% 17$ & $r q, 1 r$ & דـ • ا سنو ات \\
\hline$\%$ \%ᄉ & 79,17 & أكثر من عشر \\
\hline
\end{tabular}

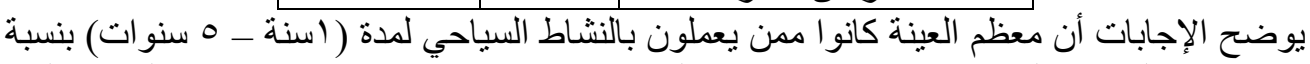

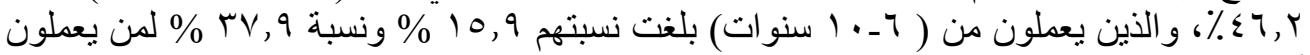

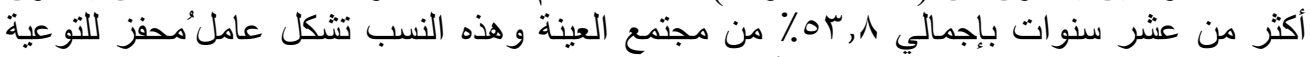

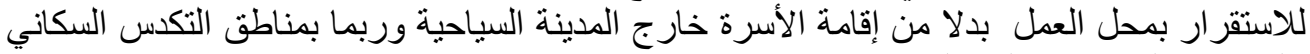
بالحافظة التي ينتمي إليها الفرد.

\section{نوع الإقامة للعاملين بالمجال السياحي} جدول (0) نوع الإقامة للعاملين بالمجال السياحي

\begin{tabular}{|c|c|}
\hline النسبة & نوع الإقامة للعاملين بالمجال السباحي \\
\hline$\% \Gamma \varepsilon, 7$ & سكن العاملين التابع لمكان العمل \\
\hline$\%$ \% r, & السكن إيجار مؤقت مع الزملاء \\
\hline$\% \circ \mathrm{V}, \mathrm{V}$ & سكن بصفة دائمة مع الأسرة بالغردقة \\
\hline$\%, r, Y$ & يسافرون يو ميا للعمل \\
\hline
\end{tabular}

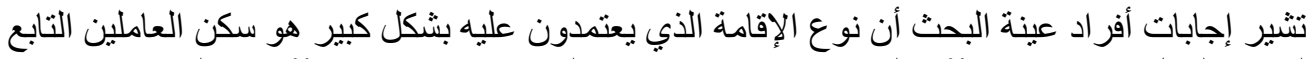

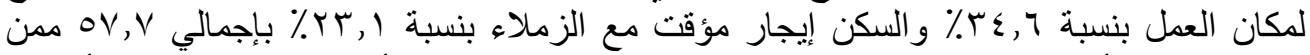

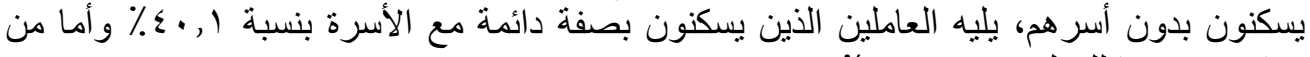

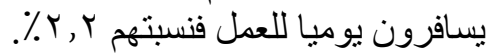




\section{البند الثاني: تقييم مستوى الخدمات بمدينة الغردقة السياحية:}

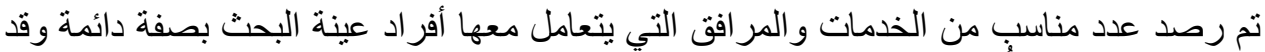

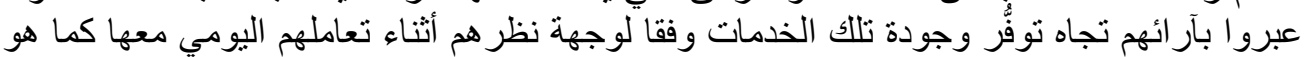
جدول (7) تقييم مستوى الخدمات بالمدينة السياحية محل العمل (الغردقة)

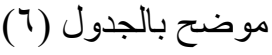

\begin{tabular}{|c|c|c|c|c|c|}
\hline غير متاح & سيئ & مقبول & جيد & ممتاز & البيان \\
\hline $9, \pi$ & $\% \leq \varepsilon, r$ & $\% \backslash, T$ & $\% 01,1$ & $\% \backslash r, T$ & وسائل النقل \\
\hline ---- & $\%$ ro, V & $\%\{\neg, r$ & $\% 17,0$ & $\% 1,7$ & مستوى الطرق \\
\hline$\%(Y, \varepsilon$ & $\% \varepsilon \Psi, \varepsilon$ & $\%(Y,\{\varepsilon$ & $\% \backslash, 1$ & $\% 1,7$ & المياه النظيفة الصالحة \\
\hline --- & $\%$ & $\% 10, \varepsilon$ & $\% 00,0$ & $\%$ \% & الكهرباء \\
\hline$\% 10, \varepsilon$ & $\% 1 \cdot, \varepsilon$ & $\% 7,7$ & $\% r V, 0$ & $\% \varepsilon \cdot, 1$ & الغاز الطبيعي \\
\hline$\% Y V, 0$ & $\% 1 \leq, r$ & $\% \wedge, 1$ & $\% \curlyvee \wedge, \gamma$ & $\% 11,0$ & الصرف الصحي \\
\hline$\% \varepsilon, q$ & $\% \varepsilon, q$ & $\%$ Y & $\% r r, T$ & $\% \varepsilon 1, r$ & وسائل الاتصالات \\
\hline--- & $\% \Pi r, r$ & $\% r q, \vee$ & $\%$ \% , & $\% \Gamma, r$ & التعليم الأساسي \\
\hline$\% r r, 1$ & $\% \Gamma \cdot, \wedge$ & $\% 10,9$ & $\%$ \% & $\% \wedge, Y$ & التعليم الجامعي \\
\hline$\% 1 r, v$ & $\%$ \% & $\% \varepsilon \cdot, 1$ & $\% 19, \wedge$ & $\%, r$ & و الخدمات الصنيةت \\
\hline$\% 7,7$ & $\% \mu, r$ & $\% \leqslant r, q$ & $\%$ \%४, & $\% 11$ & وسائل الترفيه العامة \\
\hline$\% 0,0$ & $\%(Y), \varepsilon$ & $\% \leqslant 0,1$ & $\%$ \%५, ₹ & $\% 1,7$ & مكتبات عامة و الكترونية \\
\hline --- & $\% 9,9$ & $\% \wedge, \vee$ & $\% \circ v, 1$ & $\% \leq \leq, r$ & خدمات الأغذذية \\
\hline--- & $\% 9,9$ & $\%, Y \leq, Y$ & $\% \varepsilon r, \varepsilon$ & $\%$ Yr,O & الأسو اق و المتاجر \\
\hline
\end{tabular}

توضح الدراسة الميدانية من خلال هذا البند مستوى الجودة في الخدمات الأساسية و المر افق لتوضيح نقاط القوة و الضعف بها وقد تبين من آراء أفراد عينة البحث النتائج التالية:

أفضل الخدمات التي تققدم خدمات مرضية للمو اطنين تمثلت في:

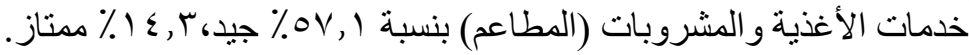

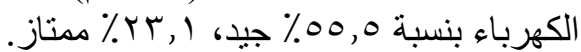

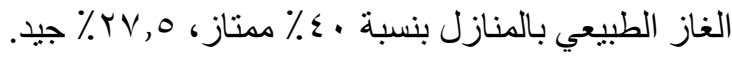

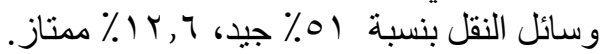

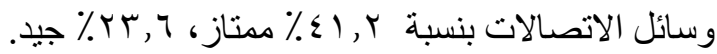

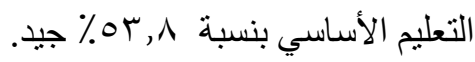




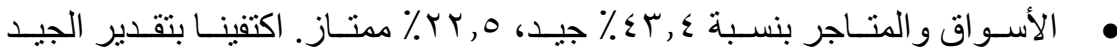

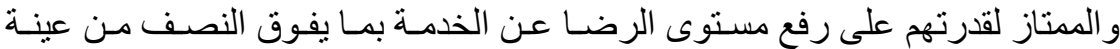

البحث وتظهر باقي النسب في الجدول فئو (ج).

أقل الخدمات التي حصلت على رضا المواطنين تمثلت في:

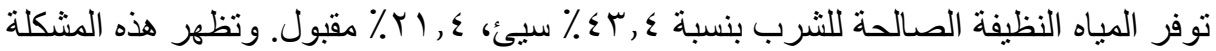

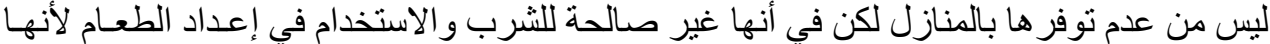

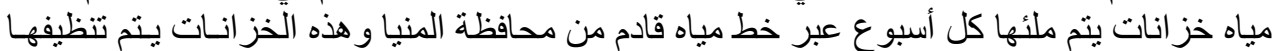

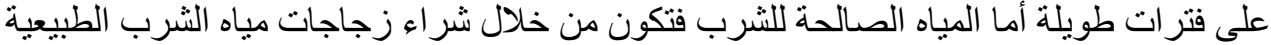

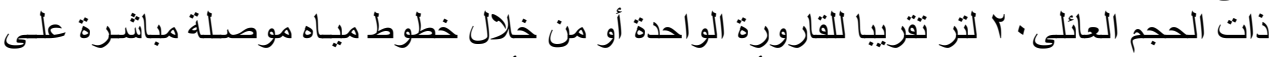

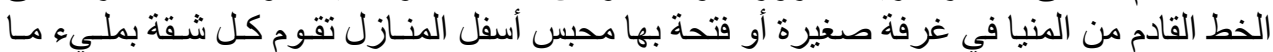

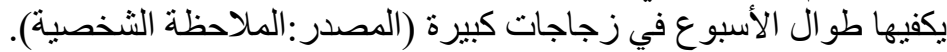

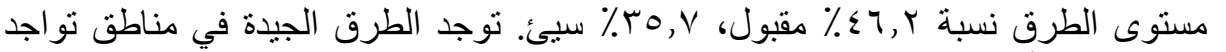

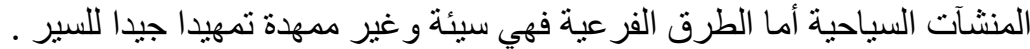

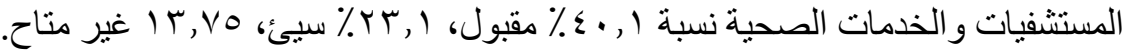

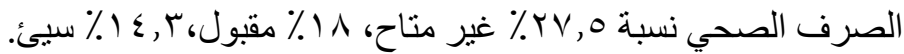

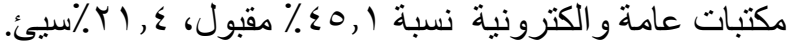

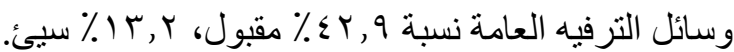

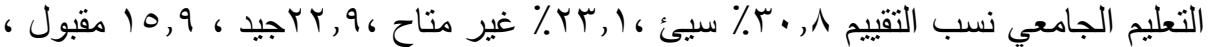
ن ^, Y

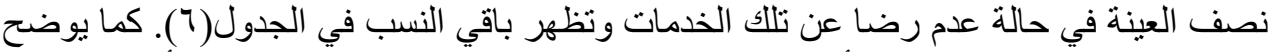

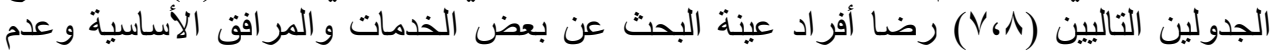

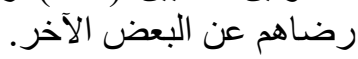
جدول (V) الوسط الحساب والانحر اف المعياري لتقييم الخدمات و المر افق الأساسية بالمدينة السياحية محل العمل (الغردقة)

\begin{tabular}{|c|c|c|c|}
\hline $\begin{array}{l}\text { الانحر اف المعياري } \\
\text { Std. Deviation }\end{array}$ & الوسط الحسابي & العدد & 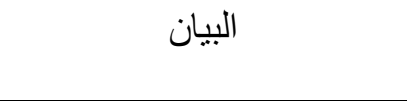 \\
\hline VOr & $r, \wedge \varepsilon$ & $1 \wedge r$ & مستوى الطرق \\
\hline 99. & $r, Y q$ & 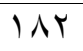 & المياه النظيفة الصالحة للشرب \\
\hline $1, \varepsilon \cdot r$ & $r, \wedge r$ & 111 & الصرف الصحي \\
\hline $1, Y \wedge 1$ & $r, 7 r$ & 111 & التعليم الجامعي \\
\hline $1, \cdot \mathrm{rA}$ & $r, V T$ & $1 \wedge r$ & المستشفيات و الخدمات \\
\hline.$\wedge \vee \neg$ & $r, 9 V$ & 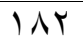 & المكتبات عامة و إلكترونية \\
\hline
\end{tabular}

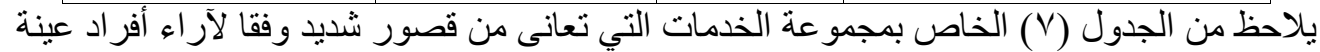

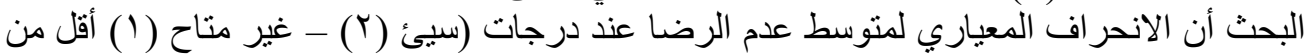

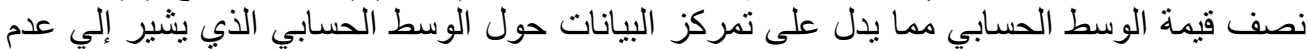

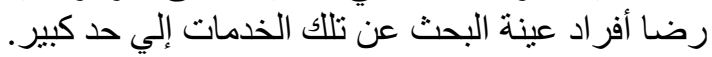


جدول (^) الوسط الحسابي و الانحر اف المعياري لتقيبم الخدمات و المر افق الأساسية بالمدينة السياحية محل

\begin{tabular}{|c|c|c|c|}
\hline \multicolumn{4}{|c|}{ العمل (الغردقة) } \\
\hline $\begin{array}{c}\text { المعياري . الانحر اف Std. } \\
\text { Deviation }\end{array}$ & الوسط الحسابي & N العدد N & البيان \\
\hline 1,17r & $r, \varepsilon r$ & $1 \wedge r$ & وسائل النقل \\
\hline Vqr & $r, 97$ & $1 / r$ & الكهرباء \\
\hline $1, \varepsilon V \Gamma$ & $r, \pi$ & $1 \wedge r$ & الغاز الطبيعي بالمنازل \\
\hline $1,1 \leqslant r$ & $r, 91$ & INT & وسائل الاتصالات \\
\hline VTr & $r, v \varepsilon$ & $1 \wedge r$ & التعليم الأساسي \\
\hline $1, \cdot Y \Lambda$ & $r, Y, r$ & $1 N r$ & وسائل الترفيه العامة \\
\hline .119 & $r, v T$ & $1 \wedge r$ & خدمات الأغذية و المشروبات \\
\hline 9.7 & $r, v q$ & $1 \wedge r$ & الأسو اق و المتاجر \\
\hline
\end{tabular}

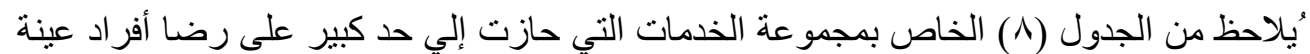

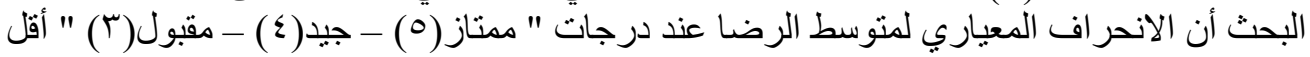

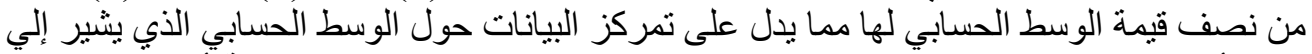

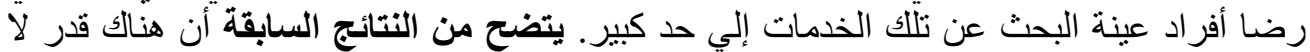

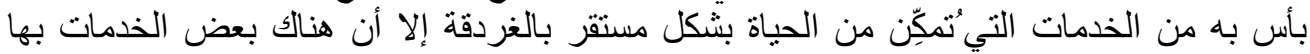

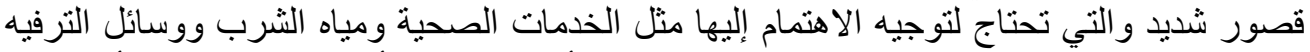

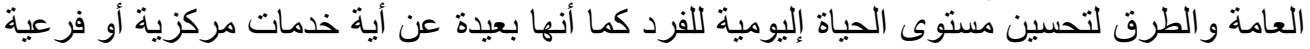

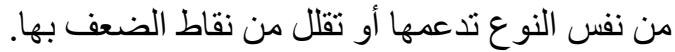

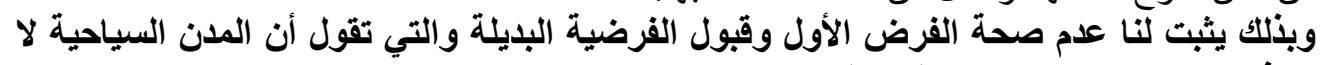
يتوفر بها مقومات الاستقرار الدائم لتكوين مجتمعات جديدة الأدرل 


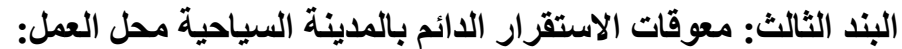

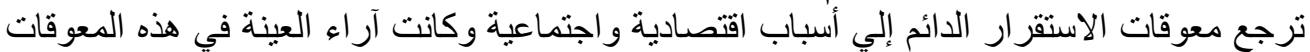
كما هو موضح بالجدول

\begin{tabular}{|c|c|c|c|c|c|}
\hline غبر مو افق بشدة & مو افق & إلي حد ما & مو افق & مو افق بشدة & البيان \\
\hline$\% \varepsilon, 9$ & $\%, v$ & $\% \wedge, \wedge$ & $\% \curlyvee \wedge, \uparrow$ & $\%$ & المتصمار فرصباب العتصادية العلى على \\
\hline$\%$ \%,$\varepsilon$ & $\% 7,7$ & $\% \uparrow, \vee$ & $\% r q, \vee$ & $\% \curlyvee q, \uparrow$ & الأستفار للسلع والخدمى العـام في \\
\hline$\% \varepsilon, 9$ & $1 \Lambda, V$ & $\%, r, q$ & $\%$ Yo, 1 & $\%$ \% , V & 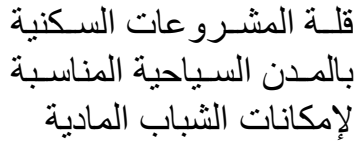 \\
\hline$\% 17,0$ & $\% r, r$ & $\% \vee, 7$ & $\%$ \%, ᄉ & $\%$ Yr,O & بالثكل توفر السلع و الخدمات \\
\hline$\% \mathrm{VV}$ & $\% r, r$ & $\% r \leq, r$ & \% & $\%|r|$, & و عادات لتنتاسب التأثر بثقافقافتات \\
\hline$\% 1 \cdot, \varepsilon$ & $\% r, r$ & $\%$ Y,$\wedge$ & $\% \pi r$ & $\% \vee \vee 7$ & 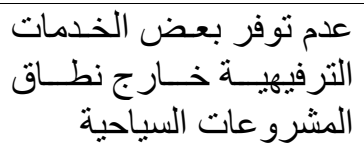 \\
\hline$\% 9, r$ & $\% r r, T$ & $\% \curlyvee \wedge, 7$ & $\% r V, 0$ & $\% 11$ & 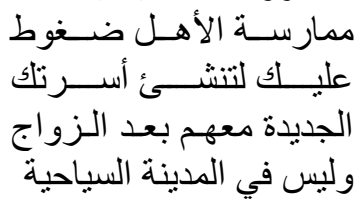 \\
\hline$\% \vee, 1$ & $\% r q, 1$ & $\% r r, 7$ & $\%$ \%, ᄉ & $\% 9, r$ & 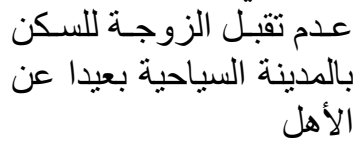 \\
\hline
\end{tabular}

$$
\text { يتضح من الجدول (9) الآتي: }
$$

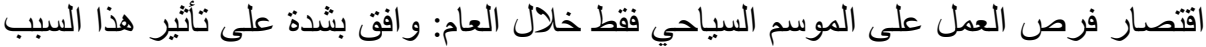

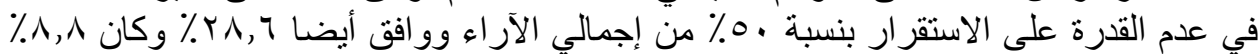

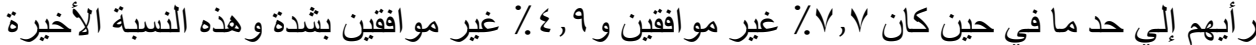

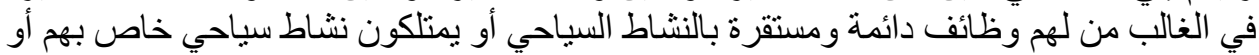
من من يعمون بالقطاع الحكومي. 


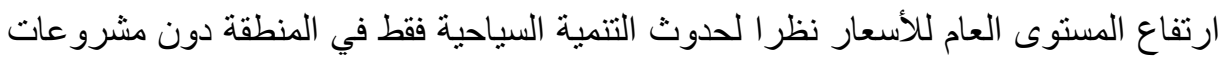

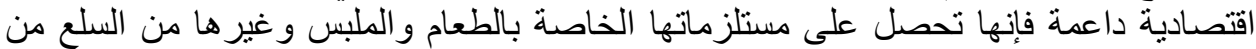

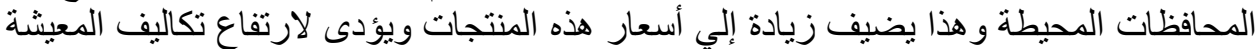

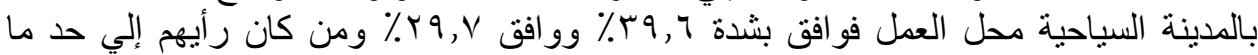

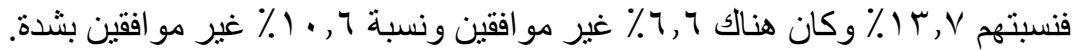

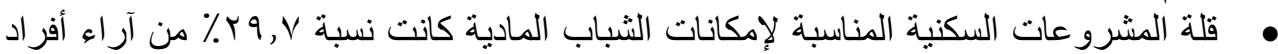

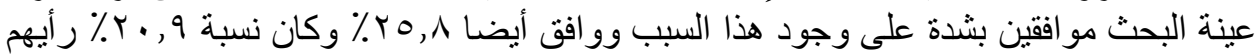

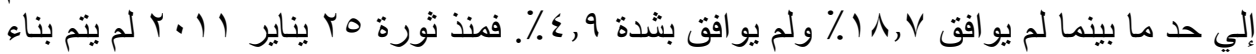

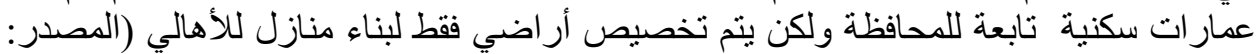
إضافات من أفراد عينة البحث).

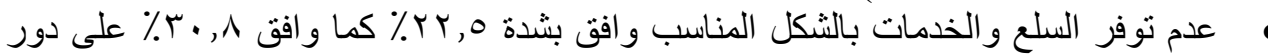

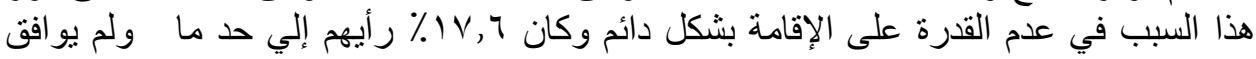

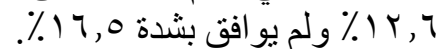

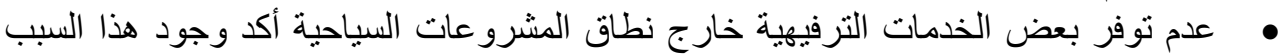

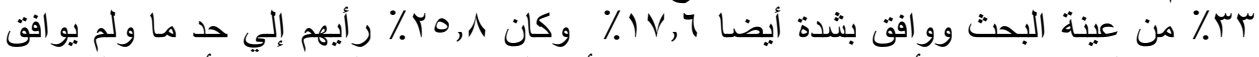

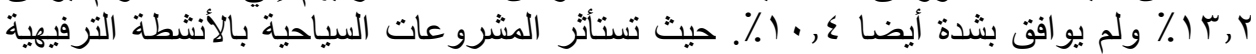

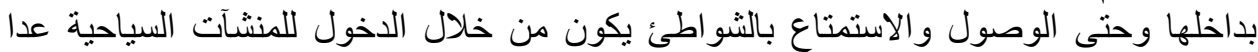

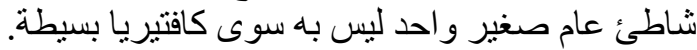

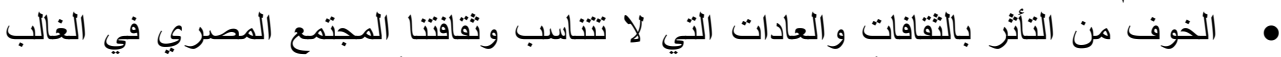

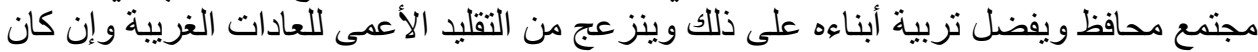

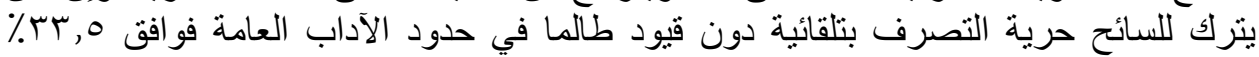

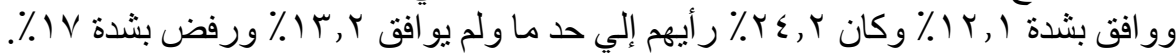

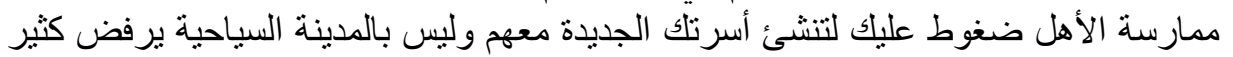

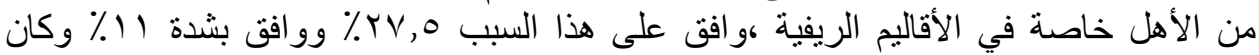

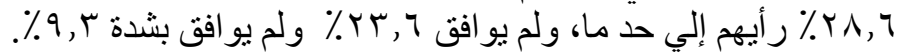

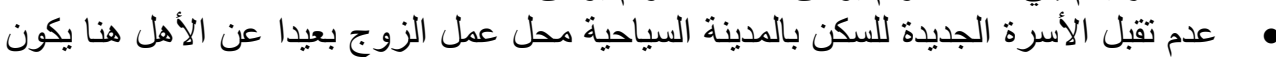

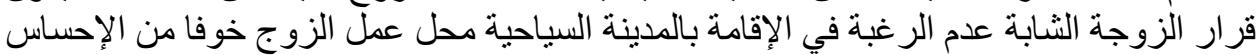

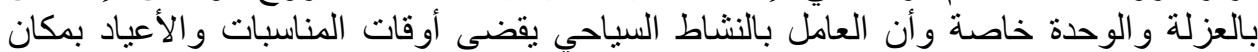

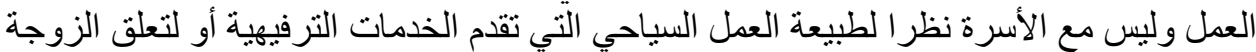

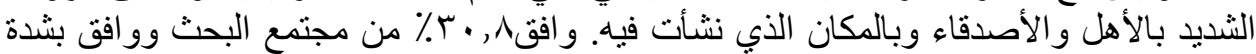

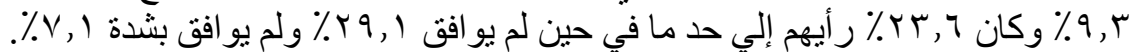


جدول ( • () الوسط الحسابي و الانحر اف المعياري لآر اء أفر اد عينة البحث حول معوقات الاستقرار الدائم

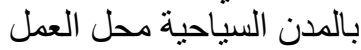

\begin{tabular}{|c|c|c|c|}
\hline 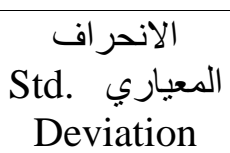 & $\begin{array}{l}\text { الحسطابي } \\
\text { Mean }\end{array}$ & 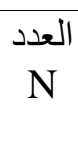 & 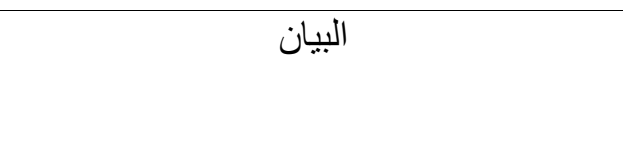 \\
\hline 1,107 & $\varepsilon, 11$ & IAr & اقتصار فرص العمل على الموسم السياحي فقط \\
\hline ।, ז. & $\Gamma, \wedge$ & $1 \wedge r$ & و الخدمات المستوى العام في الأسعار للسلع \\
\hline $1, Y M r$ & r,ov & $1 \wedge r$ & 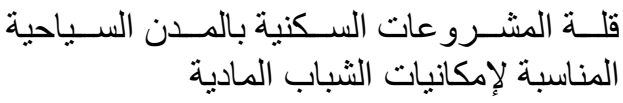 \\
\hline 1,070 & $\Gamma, \varepsilon \Lambda$ & $1 \wedge r$ & انتشار ظاهرة الغش التجاري و النصب \\
\hline $1, \pi \wedge \mu$ & $r, \mu$. & $1 \wedge r$ & عدم توفر السلع والخدمات بالشكل المناسب \\
\hline $1, Y \backslash \leqslant$ & $\Gamma, r \varepsilon$ & $1 \wedge r$ & المشر توفر بعض السياحية الخدمات الترفيهية خارج نطاق \\
\hline $1, Y V V$ & $r, 1$. & $1 \wedge r$ & والخوف من التأثز بثقافات و عادات لا تتناسب \\
\hline $1,10 r$ & $r, \cdot v$ & $1 \wedge r$ & 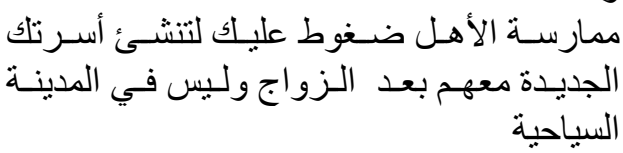 \\
\hline (1, & r, t & $1 \wedge r$ & عن الأهل الزوجة للسكن بالمدينة السياحية بعيدا \\
\hline
\end{tabular}

من الجدول (• (1) يتضح أن الانحراف المعياري لمتوسط المو افقة عند درجات " مو افق بشدة (0) -

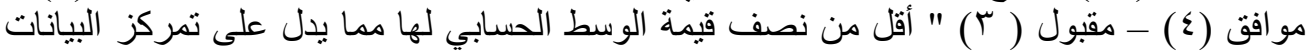

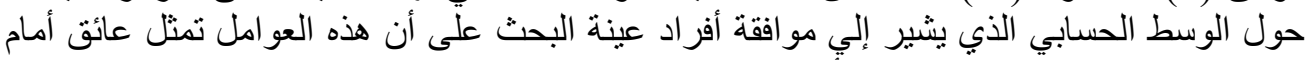

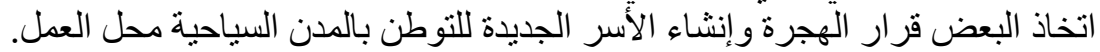

يثبت لنا صحة الفرض الثاني وهو" أنه توجد بعض العوامل التي تعوق الاستقرار الدائم بالمدن السياحية. 
البند الرابع: الآثار المترتبة على إحاثاث تنمية متكاملة سياحية واقتصادية وزراعية وحرفية في مناطق الجذب السياحي

جدول (1) الآثار المترتبة على إحداث التنمية المتكاملة السياحية لمدينة الغردقة.

\begin{tabular}{|c|c|c|c|c|c|}
\hline غئر & مو افق & إلي حد ما & مو افق & بشّدة & البيان \\
\hline --- & $\%$ & $\% 7 \leqslant, 0$ & $\% 1 \vee, 0$ & $\% 10$ & تتويع المنتج السياحي. \\
\hline --- & --- & $\% 19, r$ & $\%$ & $\% \leqslant \varepsilon, \wedge$ & تنشط الصناعات \\
\hline --- & -- & $\% 10, r$ & $\% .09,1$ & $\%$ Yo & 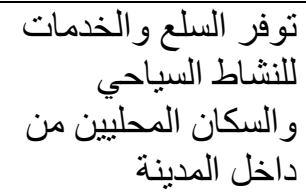 \\
\hline --- & $\%$ & $\% 11, \mathrm{~V}$ & $\%$ \% & $\% \mu \nu, r$ & ت السفافيف الضنظة بمنة الو ادي \\
\hline --- & --- & $\%$ \%O, r & $\% \leqslant 0, V$ & $\%$ \% & للتحنجات أسواق جديدة المحلية \\
\hline--- & $\% 9$ & $\% 11, r$ & $\% \leqslant 7, \vee$ & $\%$ & زالزرادية الإنتاجية الصناعية \\
\hline --- & --- & $\%, \wedge, \wedge$ & $\% \vee 0, \varepsilon$ & $\%(r, \Lambda$ & تصفة مستمرة عمل \\
\hline
\end{tabular}

يتضح من الجدول (1) (1) أن التنمية الاقتصادية بجانب النشاط السياحي لها آثار إيجابية على النشاط

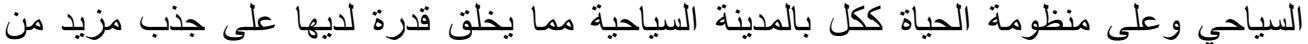

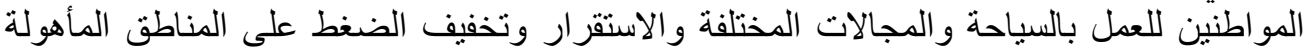

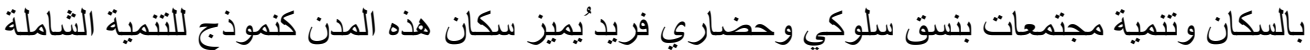

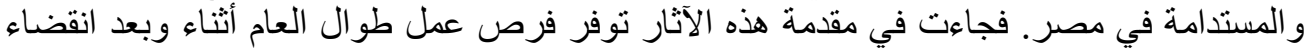

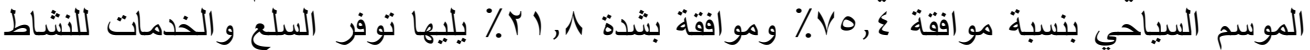

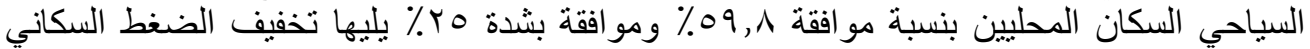

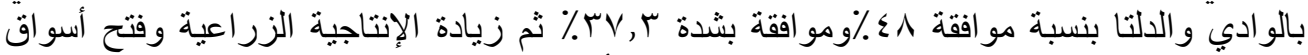

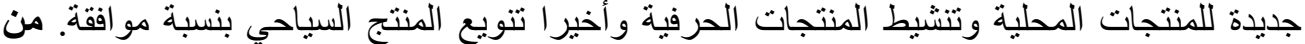

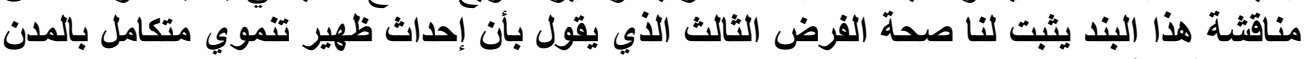
السياحية له أثر ايجابي تحقيق التوازن النكاني. 
البند الخامس: الآليات المقترحة لتحقيق التوطين السكاني بالمدينة السياحية (مدينة الغردقة)

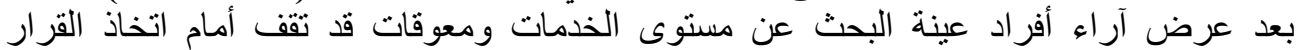

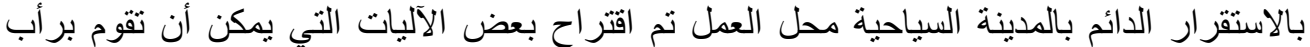

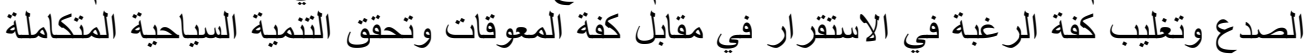

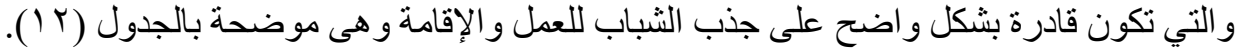
جدول (r ا ) الآليات المقترحة لتحقيق التوطين السكاني بالددن السياحية

\begin{tabular}{|c|c|c|c|c|c|}
\hline بشير بشن & 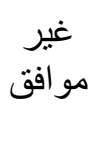 & إلي حد ما & مو افق & بشّدة & البيان \\
\hline --- & --- & $\% \backslash r, 1$ & $\% \leqslant 9,0$ & $\% \Pi \wedge, 0$ & لتمبية الخدمات السياحية المناسبة \\
\hline$\%, r, r$ & $\% 1,1$ & $\% \cdot, r$ & $\%$ \% & $\%$ Y, 0 & 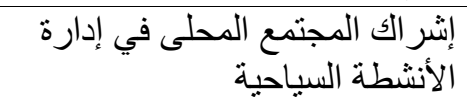 \\
\hline --- & --- & $\%) r, 7$ & $\% \varepsilon \cdot, 1$ & $\% \leqslant \vee, r$ & 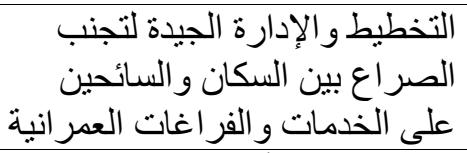 \\
\hline$\% 7$ & --- & $\% 10,9$ & $\%$ \%^ & $\% 0$. & تلناسب حجم الأعمال السياحية مع \\
\hline --- & --- & $\%$ \% , & $\% \leq \neg, V$ & $\%(r, 9$ & السكانية الخاصة خصو بالسكان المحلية المناطق \\
\hline$\% \mu, \wedge$ & --- & $\% \vee, 1$ & $\% r q, 1$ & $\% 09,9$ & 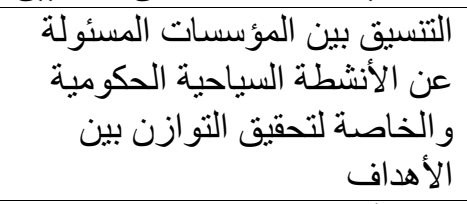 \\
\hline$\% \mu, \wedge$ & $\%, r, r$ & --- & $\% \sim_{0}, \vee$ & $\% \Delta \wedge, r$ & 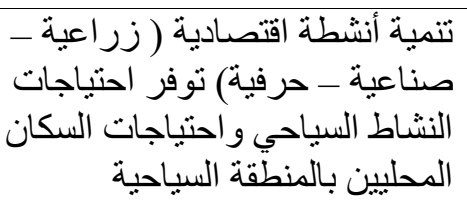 \\
\hline--- & $\% r, V$ & $\% \vee, 1$ & $\% \leqslant 0,7$ & $\% \leqslant \leqslant, 0$ & 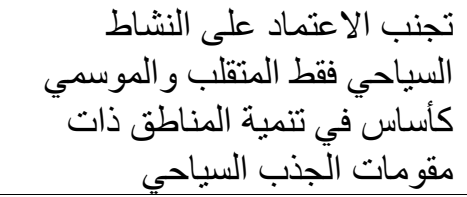 \\
\hline
\end{tabular}

$$
\text { من الجدول (r ا ) يتضح الآتي: }
$$

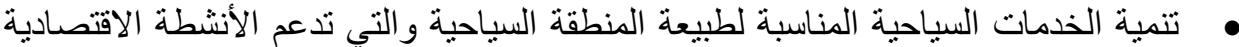

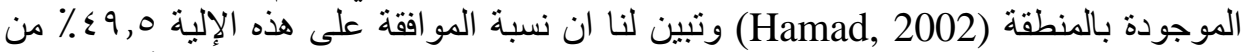

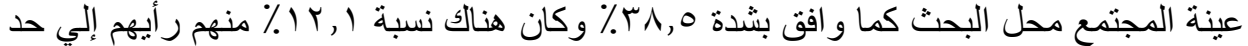

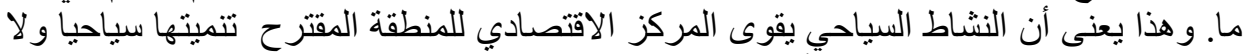
يتسبب في تجريف الإرث المهني أو الحرفي. 


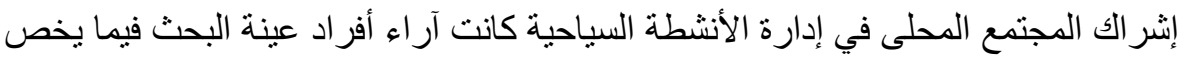

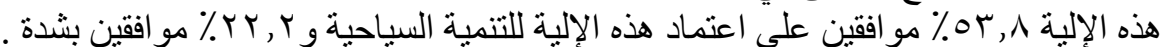

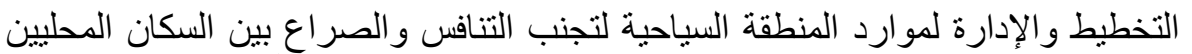

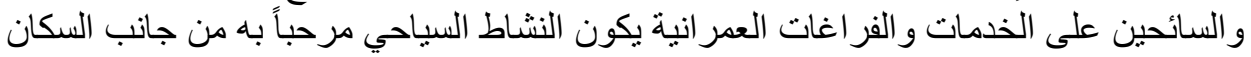

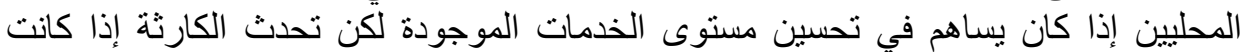

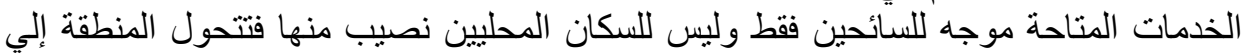

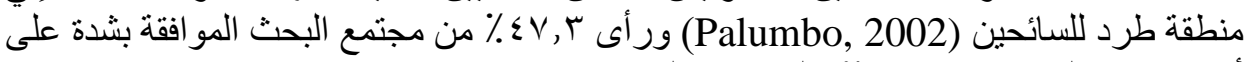

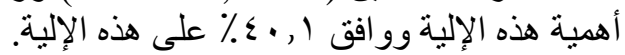

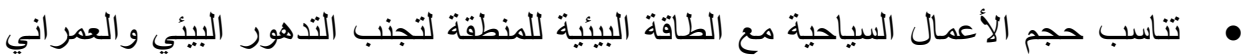

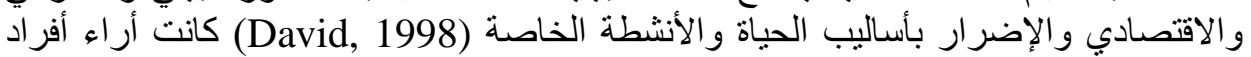

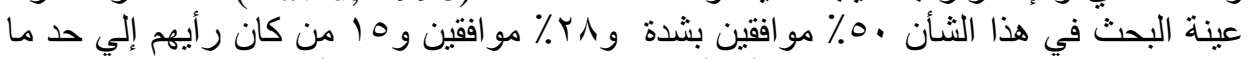

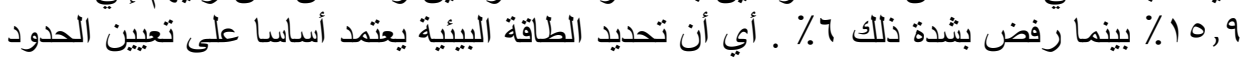
العليا للتنمية واستخدام الزوار و الاستغلاًل الأقصى للموارد السياحية مع عدم تعدى حدود الآثار

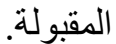

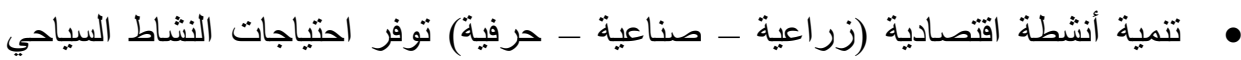

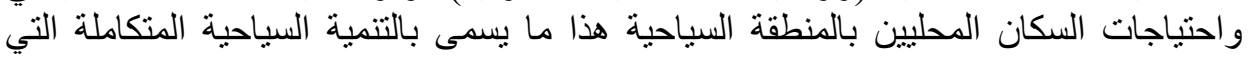

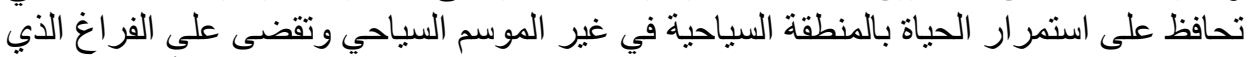

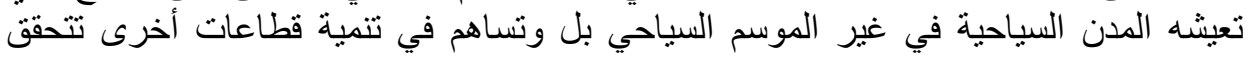

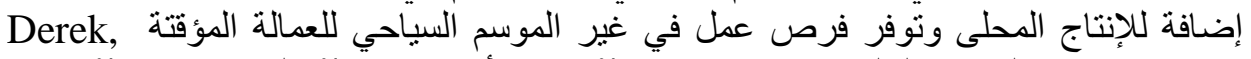

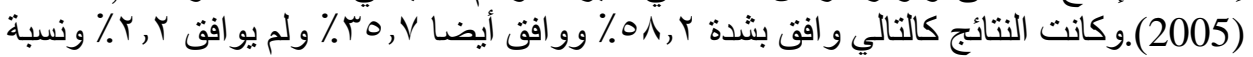

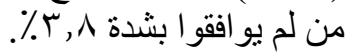

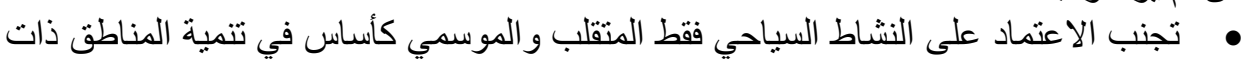

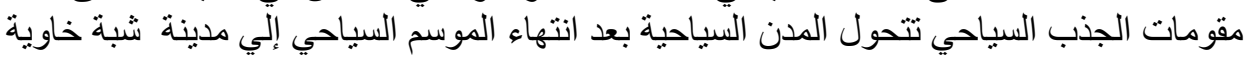

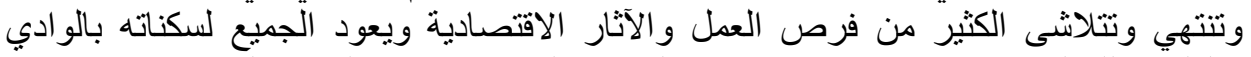

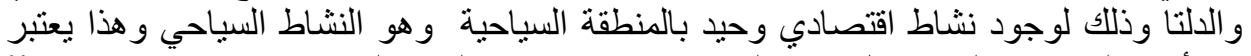

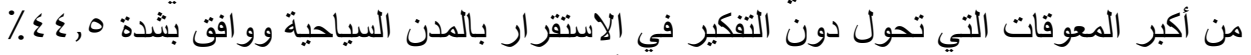

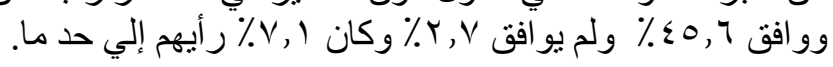

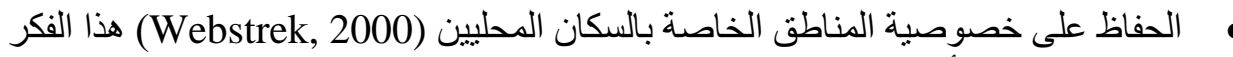

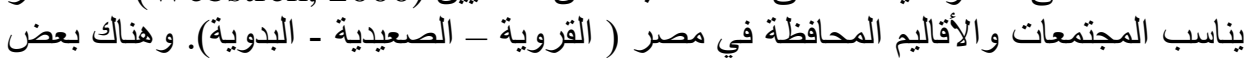

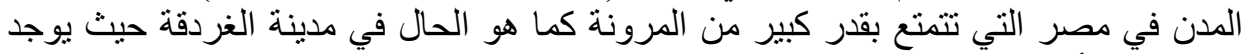

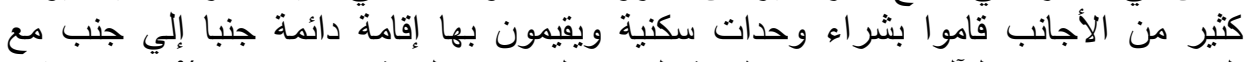

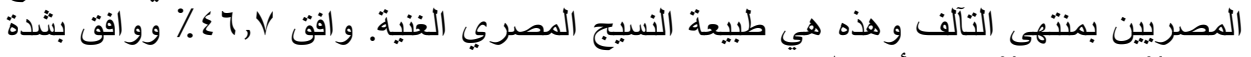

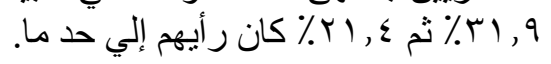

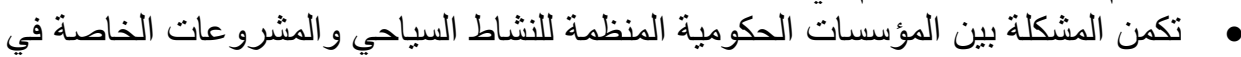

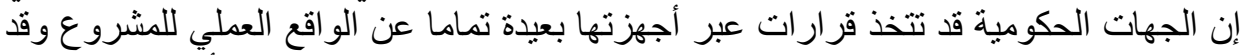

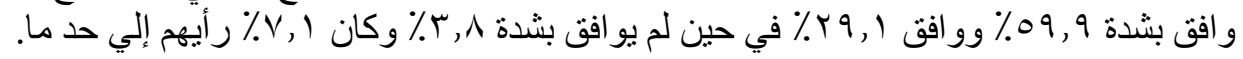




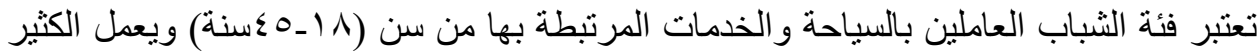

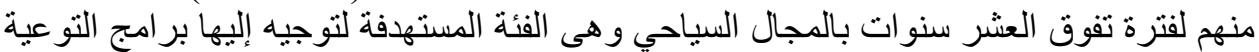

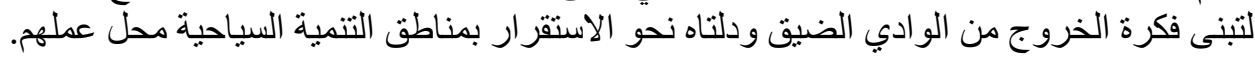

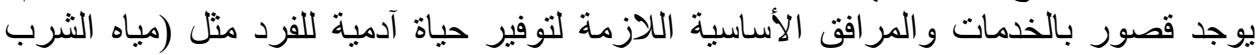

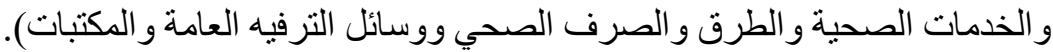

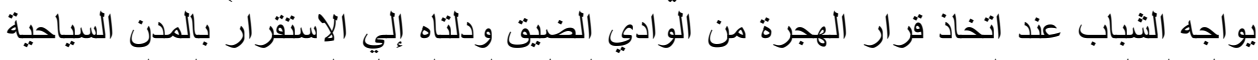

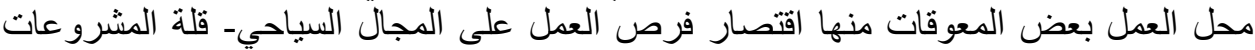

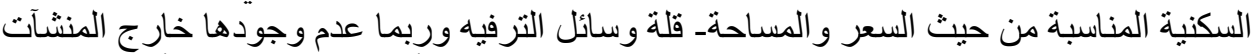

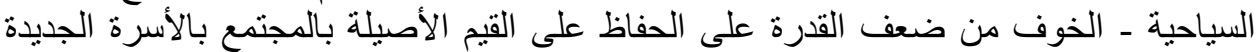

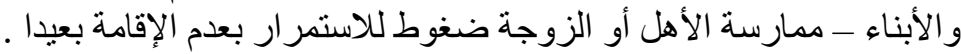

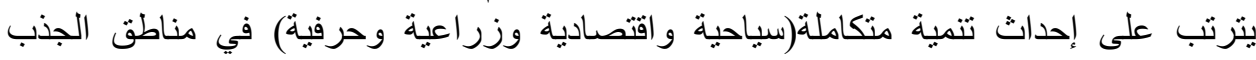

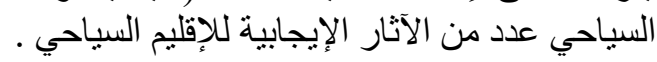
توصل البحث إلي وجود الائار عدد من الإبية الإليات التني تساهم في تحقيق التتمية السياحية المتكاملة و التوطين السكاني بالمدن السياحية.

أولا: التوصيات:

الأخذ بنظام التتمية السياحية المتكاملة كنظام جديد لإدارة المدينة ووضع أساس إيجابي لالتوسعات المستقبلية. معالجة حالات العمران العشوائي الناتج عن أسلوب استعمالات الأراضي والآثار الناتجة

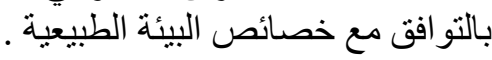

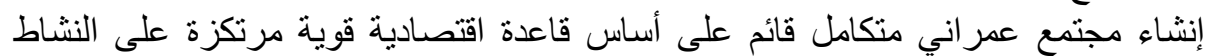

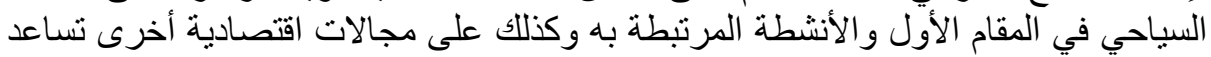

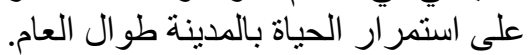

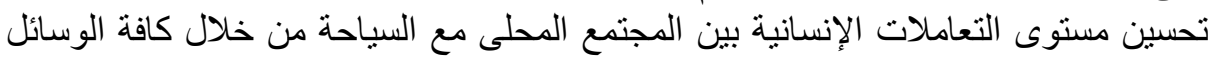

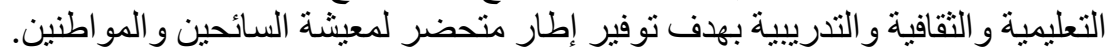

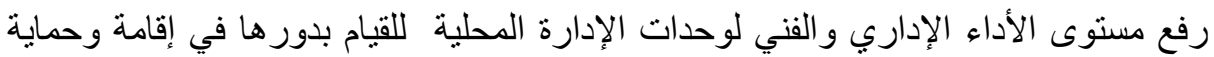
وصيانة المرافق العامة للتجمعات العمرانية بهدف نوفير بيئة عمرانية نظيفة لائقة لمعيشة

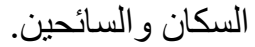
ثانياً: توصيات موجهة لوزاتِ لوارة السياحة: الاستعانة بشركات تقوم بعملية التنمية المتكاملة للمدن السياحية وليس فقط تتمية مجموعة متناثرة من المشروعات الات السياحية.

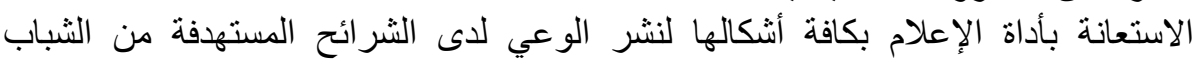

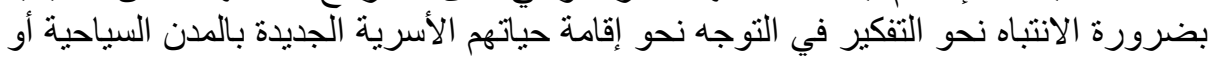
الظهير الصحر اوي لبعض المحافظات التي يمكن تنميته بعض المناطق بها لإسية سياحيا. 


\section{المراجع باللغة العربية}

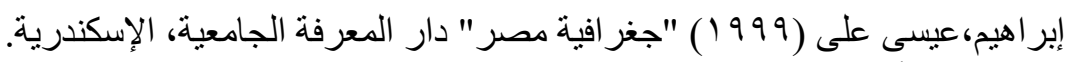

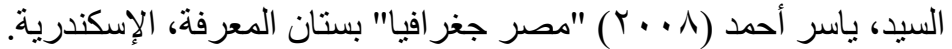

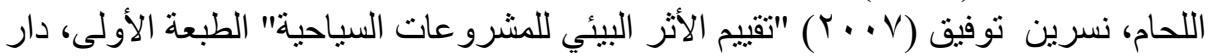

النيل للطباعة و النشر ، القاهرة.

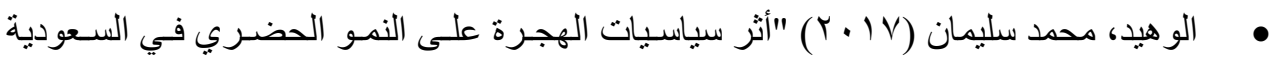

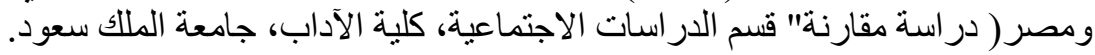

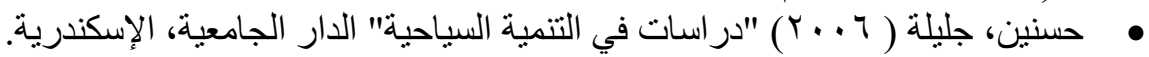

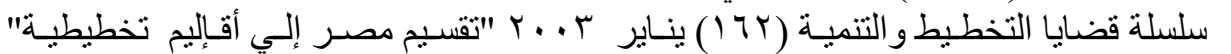

معهد التخطيط القومي، جمهورية مصر العربية العبية.

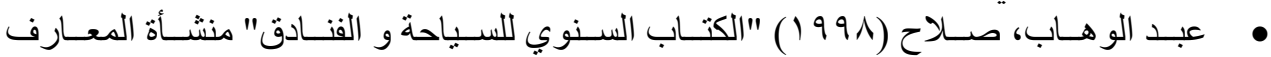

بالإسكندرية.

• كفافي، حسين (1999) "رؤية عصرية للتنمية السياحية في الدول الناميـة" الهيئة المصـرية

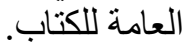

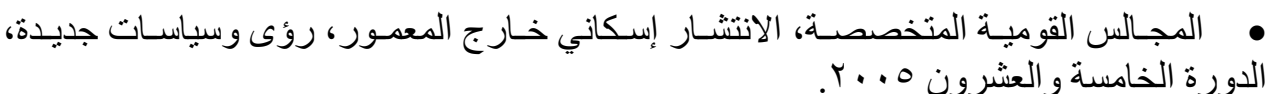

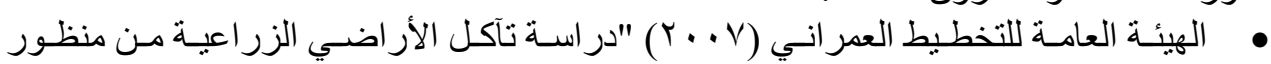

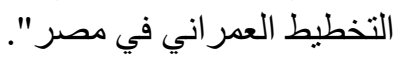

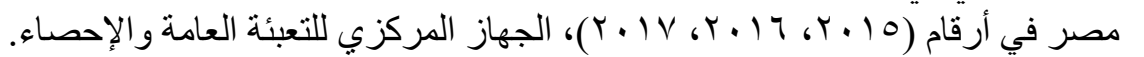

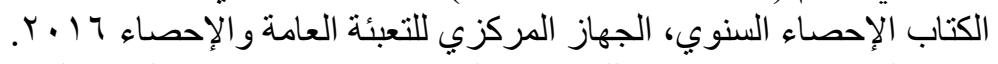

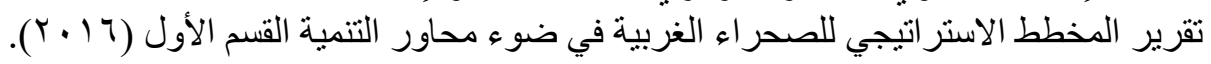

\section{المراجع باللغة الاجنبية}

- David, J. (1998).Architecture \& The Environment Bioclimatic Building Design Laurence King Publishing.

- Derek, h. Irene, K. and Morag, M. (2005).rural tourism and sustainable business, crow well press, Great Britain.

- Hamad, M. (2002).Ecological Architecture as a Resource for Sustainable Ecotourism Non published PHD, Al Azhar University.

- Palumbo, G. (2002).Management planning for Archeological Sites Teutonic, Jeeanne and - Greece p.215.

- Webstrek, k. (2000).Environmental Management in the Hospitality Industry,

Crown well press LTD, London, UK. 


\title{
Mechanisms for achieving population spread in touristic cities by applying on Hurghada city
}

\begin{abstract}
Tourism is a tool to attract population, whether rural or urban, if some other economic activities (industry / agriculture / crafts) with an appropriate amount of services and basic facilities besides tourism activity in the tourist development areas as a pillar of tourism activity in times of tourist season to provide it with the requirements of providing tourist services and provide transportation expenses The high levels of these resources, as well as a catalyst for permanent stability when the tourist movement is calm or when the tourist season ends, limiting the departure of workers in the tourist activity of these areas almost empty and their return to accumulate in the narrow valley and delta to achieve economic benefit.
\end{abstract}

Key words: The population problem, Integrated tourism development, Regional planning. 